OPEN ACCESS

Edited by:

Mauricio Antonio Retamal, Universidad del Desarrollo, Chile

Reviewed by: Davide Lecca University of Milan, Italy Annalisa Buffo

Università degli Studi di Torino, Italy

*Correspondence: Hai-Ying Shen hshen@downeurobiology.org

Lan Xiao

xiaolan35@hotmail.com

Received: 31 July 2018 Accepted: 26 November 2018 Published: 07 December 2018

Citation:

Shen $\mathrm{H}-\mathrm{Y}$, Huang $\mathrm{N}$, Reemmer $J$ and Xiao L (2018) Adenosine Actions on Oligodendroglia and Myelination in Autism Spectrum Disorder. Front. Cell. Neurosci. 12:482. doi: 10.3389/fncel.2018.00482

\section{Adenosine Actions on Oligodendroglia and Myelination in Autism Spectrum Disorder}

\author{
Hai-Ying Shen ${ }^{1,2 *}$, Nanxin Huang ${ }^{3}$, Jesica Reemmer ${ }^{1}$ and Lan Xiao ${ }^{3 *}$ \\ ${ }^{1}$ Robert Stone Dow Neurobiology Department, Legacy Research Institute, Legacy Health, Portland, OR, United States, \\ ${ }^{2}$ Department of Integrative Physiology and Neuroscience, Washington State University, Pullman, WA, United States, \\ ${ }^{3}$ Department of Histology and Embryology, Chongqing Key Laboratory of Neurobiology, Army Medical University (Third \\ Military Medical University), Chongqing, China
}

Autism spectrum disorder (ASD) is the most commonly diagnosed neurodevelopmental disorder. Independent of neuronal dysfunction, ASD and its associated comorbidities have been linked to hypomyelination and oligodendroglial dysfunction. Additionally, the neuromodulator adenosine has been shown to affect certain ASD comorbidities and symptoms, such as epilepsy, impairment of cognitive function, and anxiety. Adenosine is both directly and indirectly responsible for regulating the development of oligodendroglia and myelination through its interaction with, and modulation of, several neurotransmitters, including glutamate, dopamine, and serotonin. In this review, we will focus on the recent discoveries in adenosine interaction with physiological and pathophysiological activities of oligodendroglia and myelination, as well as ASD-related aspects of adenosine actions on neuroprotection and neuroinflammation. Moreover, we will discuss the potential therapeutic value and clinical approaches of adenosine manipulation against hypomyelination in ASD.

Keywords: adenosine receptor, oligodendroglial differentiation, demyelination, neurotransmitter, autism

\section{INTRODUCTION}

Autism spectrum disorder is a range of neurodevelopmental conditions characterized by impairments in verbal and non-verbal communications, social skills, and repetitive behaviors. The variety of presentations of ASD is due to complex combinations of environmental and genetic influences; indeed, the term spectrum itself reveals the diversity of strengths and differences in symptoms of each autism patient. According to the reports, the average prevalence of individuals suffering from ASD is about $1 \%$ of people worldwide (Murray et al., 2014). ASD usually begins in childhood and tends to persist into adulthood, sometimes causing severe disabilities that call for life-long care and support.

Abbreviations: 5-HT, 5-hydroxytryptamine; $A_{1} R$, adenosine $A_{1}$ receptor; $A_{2 A} R$, adenosine $A_{2 A}$ receptor; $A_{2 B} R$, adenosine $A_{2 B}$ receptor; $A_{3} R$, adenosine $A_{3}$ receptor; $A D A$, adenosine deaminase; $A D K$, adenosine kinase; AMPAR, $\alpha$-amino- 3 hydroxy-5-methyl-4-isoxazolepropionic acid receptor; ASD, autism spectrum disorder; BBB, blood-brain barrier; cAMP, cyclic adenosine monophosphate; CB1R, cannabinoid receptor (type 1); $D_{1} R$, dopamine D1 receptor; $D_{2} R$, dopamine D2 receptor; $D_{3} R$, dopamine $D 3$ receptor; EAE, experimental allergic encephalomyelitis; GABA, gamma-aminobutyric acid; IL, interleukin; MS, multiple sclerosis; NMDAR, $N$-methyl-D-aspartate receptor; NTs, nucleotide transporters; OL, oligodendrocyte; OPC, oligodendrocyte precursor cell; SAH, S-adenosyl-L-homocysteine; TLR, toll-like receptor. 
Although the underlying mechanisms of ASD remain unclear, the most common hypothesis has been that of disrupted cerebral connectivity during brain development - this model proposes that ASD patients have reduced connections between distant brain regions and increased connections within local regions; such a disarranged connectivity could underlie the observed abnormalities in social, cognitive, and behavioral functions (Belmonte et al., 2004). During early brain development, aberrations appear in cytoarchitectural organizations in the frontal lobe, parieto-temporal lobe, subcortical limbic structures and cerebellum (Fombonne et al., 1999; Bolton et al., 2001; Courchesne, 2004; Hazlett et al., 2005). In addition, it has further been shown that ASD patients experience multiregional abnormalities in neurogenesis, neuronal migration, and maturation (Wegiel et al., 2010; Chen et al., 2015). However, the neuronal connectivity hypothesis of ASD is not fully supported, due to inconsistent data that reveals long-range hyper-connectivity or mixed patterns of both hypo- and hyper-connectivity (Mizuno et al., 2006; Turner et al., 2006; Noonan et al., 2009; Shih et al., 2010). Recently, increasing evidence suggests that white matter and myelin abnormalities are more relevantly involved in ASD pathophysiology. For example, neuroimaging studies utilizing diffusion tensor imaging (DTI) and magnetic resonance imaging (MRI) show that white matter disruption occurs in brain regions of children with ASD (Carmody and Lewis, 2010). Molecular genetic studies also reveal aberrations of myelin-related genes in ASD patients, both in expression level and epigenetic regulation (Richetto et al., 2017). Moreover, chromatin-remodeling protein CHD8, an ASD susceptibility gene, has also been found to play a vital role in oligodendroglial development and remyelination (Zhao et al., 2018).

In addition to studies focusing directly on structural variation, there coexists exciting research into the purine ribonucleoside adenosine; as a neuro- and glia-modulator, adenosine can directly and indirectly interact with several neurotransmitters, including glutamate, dopamine, and GABA, to regulate the development of oligodendroglial cells and myelination (Stevens et al., 2002). Also, by modulating neurotransmitters, adenosine has been shown to affect certain ASD comorbidities and symptoms, such as epilepsy, impaired cognitive functions, and anxiety (Fredholm et al., 2005a,b). In this review, we will summarize and discuss the interaction between adenosine signaling system in the central nervous system (CNS), mainly focusing on its effect in oligodendrocytes and the clinical symptoms of ASD, as well as the related cellular and molecular abnormalities. We suggest that augmentation of the useful actions of adenosine may become a potential therapeutic approach for the treatment of ASD by affecting myelination.

\section{ADENOSINE METABOLISM AND ADENOSINE RECEPTORS}

Adenosine is ubiquitously found in CNS. Early studies implied that adenosine was merely a metabolite of ATP and cAMP; now adenosine is widely recognized as a neuromodulator, gliomodulator, and modulator of complex behaviors with a broad range of biological and pathological functions. Indeed, adenosine plays two important roles in the CNS: (i) as a homeostatic transcellular messenger between neuronal and glial cells and (ii) as a modulator controlling neurotransmitter release and reuptake for neuronal excitability (Shen and Chen, 2009; Boison and Shen, 2010; Shen et al., 2012).

\section{Adenosine Metabolism}

Adenosine metabolism in the CNS has been extensively reviewed elsewhere (Cunha, 2001; Latini and Pedata, 2001; Fredholm et al., 2005a,b). Unlike classical neurotransmitters, which are stored in synaptic vesicles and released by exocytosis for exclusive actions on synapses (Fredholm et al., 2005a,b), adenosine distributes extra- and intra-cellularly throughout tissues in the CNS and maintains a basal level in the range of 50-200 nM (Latini and Pedata, 2001). The intra- and extra-cellular adenosine levels exist in a state of dynamic exchange due to the influence of both equilibrative and concentrative nucleoside transporters (Baldwin et al., 2004; Gray et al., 2004). Additionally, metabolic enzymes such as ADA, ADK, SAH-hydrolase, and NTs, continually cycle adenosine through a variety of pathways (Boison and Shen, 2010). The input sources of adenosine are also varied, though strictly dependent on the metabolic state of the cell. Extracellularly, adenosine is produced by the breakdown of adenine nucleotides (such as ATP) by a variety of ecto-NTs, which include ectonucleoside triphosphate diphosphohydrolase CD39 and the $5^{\prime}$ nucleotidase CD73. Intracellularly, adenosine can be generated via the dephosphorylation of AMP or the hydrolysis of SAH by cytosolic enzymes $5^{\prime}$-NT or SAH-hydrolase, respectively (Schubert et al., 1979; Broch and Ueland, 1980) (Figure 1).

In the CNS, adenosine levels are largely regulated by glial cells, and two main types of equilibrative adenosine transporters that exist in astrocytic membranes. Intracellular removal of adenosine is executed by degradation to inosine or phosphorylation to AMP by ADA and ADK, respectively (Pak et al., 1994; Boison et al., 2010). The release and uptake of adenosine are mediated by bidirectional nucleoside transporters, depending on the adenosine concentration gradient between the extracellular and intracellular spaces (Gu et al., 1995). It is also worth pointing out that of adenosine levels between extracellular and intracellular spaces are usually maintained in the same range due to highly efficient cellular equilibrative nucleoside transporters in most cells for facilitated diffusion (Cass et al., 1999).

\section{Adenosine Receptors and Neurotransmissions}

As a key neurotransmitter, adenosine signaling plays a significant role in neuronal excitability and neuroprotection, as well as synaptic and non-synaptic neurotransmission in the CNS. The adenosinergic system also interacts with several other major neurotransmitters, such as dopamine, glutamate, acetylcholine noradrenaline, serotonin (5-hydroxytryptamine), and endocannabinoids (Sperlagh and Vizi, 2011; Shen et al., 2013); these interactions have, however, been reviewed and discussed extensively (Sebastiao and Ribeiro, 2000; 


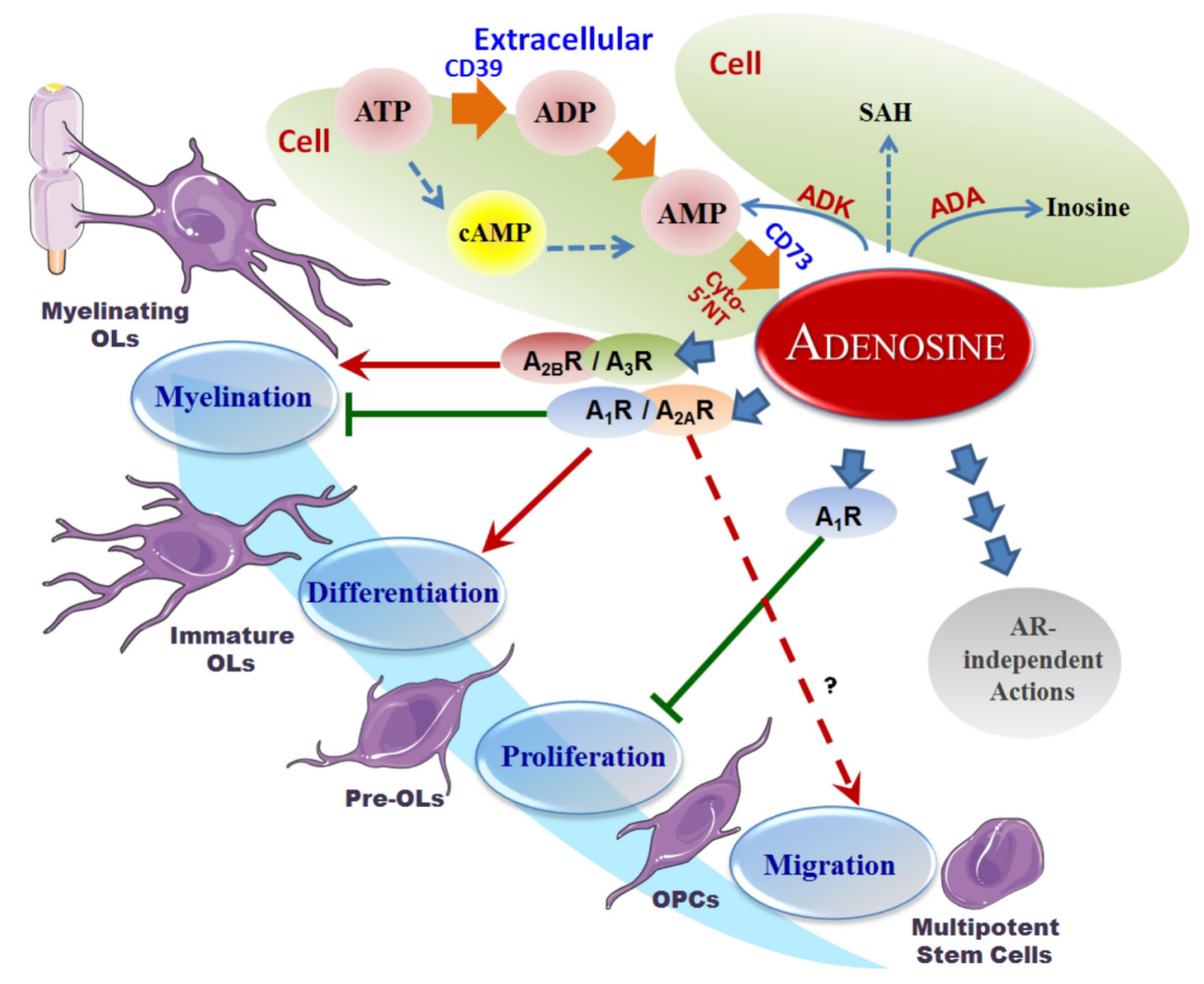

FIGURE 1 | Adenosine metabolism and its effects on OPCs. Overview of the adenosine metabolism and adenosine receptor-induced actions on oligodendroglial development. It is seen that $A_{1} R$ inhibits oligodendroglial proliferation, $A_{1} R$ and $A_{2 A} R$ promote differentiation and inhibit myelination, and $A_{2 B} R$ and $A_{3} R$ promote myelination in the lifecycle of oligodendrocytes. The pool of extracellular adenosine is responsible for the activation of these various ARs, while itself being the subject of supply by the ATP cycle, metabolism by hydrolysis or deamination, as well as transport and internalization. Red arrows represent a stimulation effect; Green bars represent an inhibition effect; Blue arrows show the directionality of effects.

Fredholm et al., 2005a,b; Chen et al., 2013). Of particular interest in this review is the ability of adenosine to modulate neurotransmitter release and neuronal excitability in the CNS via activation of four different subtypes of G-protein coupled adenosine receptors (ARs): $A_{1} R, A_{2 A} R, A_{2 B} R$, and $A_{3} R$ (Fredholm et al., 2005a,b). Through ARs, adenosine influences a wide range of brain functions under physiological and pathophysiological conditions, including neuroprotection, neuroinflammation, sleep, psycholocomotion, anxiety, cognition and memory, and neuropsychological disorders (Dunwiddie and Masino, 2001; Fredholm et al., 2005a,b; Shen et al., 2008, 2012). The interactions among subtypes of ARs and between adenosinergic signaling and other neurotransmissions may involve molecular mechanisms at multiple levels, such as (i) direct cross-talk between receptors on the cell membrane, (ii) downstream intracellular second messenger systems among different receptors, (iii) transsynaptic actions, and (iv) interactions between neurons and glial cells (Sebastiao and Ribeiro, 2000; Stevens et al., 2002; Dare et al., 2007; Shen and Chen, 2009; Boison et al., 2010).
Through AR-dependent actions, adenosine modulates the release of several neurotransmitters in the CNS, including dopamine, glutamate, GABA, serotonin, noradrenaline, acetylcholine, and cannabinoids (Fredholm and Dunwiddie, 1988; Cunha, 2001; Dunwiddie and Masino, 2001). Among the four subtypes of $A R s, A_{2 A} R$ and $A_{1} R$ play the most significant roles in the interaction between the adenosinergic signaling pathway and other neurotransmitters, while $\mathrm{A}_{2 \mathrm{~A}} \mathrm{R}$ and $A_{3} R$ have a limited effect (Fredholm et al., 2005a,b; Chen et al., 2013). Even so, the AR-mediated manipulations on neurotransmissions involve a high degree of complexity (Dixon et al., 1997; O’Kane and Stone, 1998; Lopes et al., 1999; Gorter et al., 2002). Firstly, this regulation is primarily mediated by the interplay of $A_{1} R$ and $A_{2 A} R s$, as these two subtypes have different partnering sets of G-proteins mediating opposing excitatory vs. inhibitory actions. Specifically, the activation of $\mathrm{G}_{\mathrm{i} / \mathrm{o}}$-coupled $A_{1} R$ (and $A_{3} R$ ) mediates the adenosine-dependent inhibition of neurotransmitter release at pre-synaptic neuronal terminals and represses post-synaptic neuronal (Snyder, 1985; Fredholm and Dunwiddie, 1988; Latini et al., 1996). Contrastingly, activation of $\mathrm{G}_{\mathrm{s}}$ olf-coupled $\mathrm{A}_{2 \mathrm{~A}} \mathrm{R}$ (and $\mathrm{A}_{2 \mathrm{~B}} \mathrm{R}$ ) exerts excitatory activity of 
stimulating the release of glutamate, acetylcholine, and GABA in the striatum and hippocampus (Kirkpatrick and Richardson, 1993; Kirk and Richardson, 1994; Cunha et al., 1995a,b; Sebastiao and Ribeiro, 1996). Secondly, the actions from pre- and postsynaptic sites also contribute to the complexity of AR actions. Presynaptically, stimulation of $\mathrm{A}_{1} \mathrm{R}$ suppresses the release of transmitters including dopamine, glutamate, 5-HT, acetylcholine, GABA, and noradrenaline; whereas activation of presynaptic $\mathrm{A}_{2 \mathrm{~A}} \mathrm{R}$ facilitates the release of acetylcholine, GABA, and glutamate (Sperlagh and Vizi, 2011). Post-synaptically, activation of $A_{2 A} R$ inhibits activity of dopamine $D_{2}$ receptor $\left(D_{2} R\right)$, while $A_{1} R$ activation counteracts functions of dopamine $D_{1}$ receptor $\left(D_{1} R\right)$ (Ferre et al., 1991; Fredholm et al., 2005a). A 2 A Rs serve a permissive role in activating cannabinoid receptor (type 1) (CB1R)-mediated inhibition of excitatory transmission, while $\mathrm{A}_{1} \mathrm{R}$ prevents the $\mathrm{CB} 1 \mathrm{R}$-mediated reduction of glutamate release. In addition, adenosine signaling affects the activity of postsynaptic AMPAR and NMDAR by control of glutamate release (Sebastiao and Ribeiro, 2009; Sperlagh and Vizi, 2011). Thirdly, the formation of these AR heteromeric receptor complexes also allows for their regulation at the second messenger level. For example, ARs can form heteromers between ARs themselves or with other receptor types, such as glutamate receptors, dopamine $D_{1}$ and $D_{2}$ receptors, or cannabinoid receptors. While the $A_{2 A} R$ $\mathrm{D}_{2} \mathrm{R}$ heteromers are the first demonstrated epitope-epitope electrostatic interactions underlying receptor heteromerization (Ferre et al., 2004), the capability of $A_{1} R$ and $A_{2 A} R$ to form homo- or hetero-oligomers with both other receptors and ARs alike has widened their biological roles in developmental, physiological, and pathological situations. In addition to AR actions, studies suggest that adenosine regulating enzymes may also affect epigenetic modifications (Kiese et al., 2016), including alteration of transmethylation and histone modifications (Borea et al., 2016). All of the above regulatory levels comprise a high degree of complexity of adenosinergic actions.

\section{ADENOSINE'S EFFECT ON OLIGODENDROGLIAL DEVELOPMENT}

In the CNS, the development of the oligodendrocytes lineages (OLs) is a crucial step for myelination, which is essential for the normal functioning of transduction between neurons. Adenosine actions play a crucial role in this process (Fields, 2006) via AR-mediated direct effects and/or actions from AR-interacted neurotransmissions. Prior to myelination, oligodendroglial cells pass through distinct stages, including OPCs, pre-mature OLs, and finally mature OLs. It has been shown that all subtypes of ARs (i.e., $A_{1} R, A_{2 A} R, A_{2 B} R$, and $A_{3} R$ ), along with $A D A, A D K$, and the equilibrative nucleoside transporters, ENT1 and ENT2, are expressed on oligodendroglial cells (Gonzalez-Fernandez et al., 2014). Adenosinergic signaling has various effects on oligodendroglia via the activation of ARs and changes in adenosine metabolism (Stevens et al., 2002), while adenosine actions on oligodendroglial development and OL maturation are AR subtype-dependent (Burnstock et al., 2011a,b). For example, adenosine can act through $\mathrm{A}_{1} \mathrm{R}$ activation to inhibit the proliferation of OPC but also can promote the differentiation of OPCs into myelinating OLs (Stevens et al., 2002; Asghari et al., 2013). In contrast, adenosine acting through $A_{2 A} R$ activation can inhibit $\mathrm{OL}$ maturation, whereas inactivation of $\mathrm{A}_{2 \mathrm{~A}} \mathrm{R}$ can delay the differentiation of OPCs via altered rectifier potassium currents in culture (Coppi et al., 2013). Also, the $\mathrm{A}_{2 \mathrm{~A}} \mathrm{R}$ agonist CGS-21680 can mediate OPC differentiation, which in turn can be completely blocked by the selective $\mathrm{A}_{2 \mathrm{~A}} \mathrm{R}$ antagonist $\mathrm{SCH}$ 58261. In addition, the activation of $A_{3} R$ by its agonist 2-CIIB-MECA can cause concentration-dependent oligodendroglial cell death. This mechanism is ultimately due to disruption of mitochondrial membrane potential in oligodendroglial cells; through activation of Bax and Puma proapoptotic proteins, $\mathrm{A}_{3} \mathrm{R}$ mediates apoptosis and necrosis (Gonzalez-Fernandez et al., 2014). Nevertheless, adenosine is suggested to not only inhibit proliferation of OPCs, but also stimulate the migration and differentiation of OPCs and promote myelin formation (Stevens et al., 2002; Othman et al., 2003; Karadottir and Attwell, 2007); further studies are still needed to dissect these seemingly contradictory roles of ARs and adenosine modulating enzymes.

\section{NEUROTRANSMITTER-MEDIATED ACTIONS OF ADENOSINE ON OLIGODENDROGLIAL DEVELOPMENT}

\section{Glutamatergic Effects}

The proliferation and differentiation of OPCs, as well as their capability to myelinate axons, are partly controlled by neurotransmitters linked to adenosine modulation; the activation of these neurotransmitter receptors contributes to the damage of OLs and disrupted myelination in pathological scenarios (Karadottir and Attwell, 2007; Kolodziejczyk et al., 2009; Hamilton et al., 2017). For example, glutamate receptors are expressed in oligodendroglial cells and affect their development (Karadottir et al., 2005). Under normal physiological conditions, glutamate acts through the activation of NMDAR to increase OPC migration, whereas activation of the AMPAR or kainate receptors (but not NMDAR) decreases the proliferation of OPCs (Karadottir and Attwell, 2007) by altering both intracellular sodium concentration and potassium channel function. Blocking NMDA receptors with phencyclidine will result in the inability of OLs to mature (Lindahl et al., 2008).

\section{Dopaminergic and Other Neurotransmitters' Effects}

Dopamine has been reported to modulate CNS myelination (Belachew et al., 1999) through underlying mechanisms that are not fully elucidated. It was found that the dopamine antagonist haloperidol increases OPC proliferation but inhibits their differentiation, an action likely to occur via $\mathrm{D}_{3} \mathrm{R}$ (Bongarzone et al., 1998). To clarify the effect of the different subtypes of dopaminergic receptors involved in oligodendroglial development, genetic approaches may need to be utilized in the future. OPCs also express acetylcholine receptors, and the activation of muscarinic acetylcholine M3 receptors increases 
OPC proliferation through activation of the MAPK signaling pathway; conversely, anti-muscarinic treatment has been seen to accelerate functional myelin repair (Abiraman et al., 2015). Meanwhile, inactivation of nicotinic acetylcholine receptors (nAChR) can inhibit proliferation of OPCs, as evidenced by the ability of the nAChR antagonist mecamylamine to suppress OPC differentiation (Imamura et al., 2015).

Together, while the adenosinergic system plays crucial roles in glutamatergic and dopaminergic neurotransmissions at multiple molecular and cellular levels (Stevens et al., 2002; BarneaGoraly et al., 2004; Matos et al., 2015), the studies in this section suggest that adenosine signaling can influence the regulation of oligodendroglial development and remyelination via neurotransmitters' actions itself.

\section{ADENOSINE AND ADENOSINE RECEPTORS IN DEMYELINATION AND REMYELINATION}

Various studies have shown that myelin abnormalities are involved in ASD, affecting information processing and cognition. Researchers utilized MRI scans to compare myelination between ASD and neurotypical children, and found that children with ASD had more myelinated neural fiber than the average level of similarly aged children in both the left and right medial frontal cortex, but had less myelination in the left temporoparietal junction (Deoni et al., 2015). Another study using DTI found that the fractional anisotropy value - an index used to describe the statistical difference in white matter brain scanning - was reduced in the white matter in children and adolescents with autism compared to controls, including regions adjacent to the superior temporal sulcus, ventromedial prefrontal cortices, anterior gyri, and temporoparietal junctions and corpus callosum, as well as regions adjacent to the temporal lobes close to the amygdala. This suggests that white matter disruption between brain regions may cause impaired social cognition in autism (Ginsberg et al., 2012). Measurement of myelin content by performing crosssectional imaging of fractional anisotropy - based on the movements of water molecules - showed that the global myelin water fraction was significantly lower in autism patients than in neurotypical controls (Stolerman et al., 2016). By applying whole genome DNA methylation microarrays analysis and high-resolution whole-genome gene expression, researchers have found that changes in myelin and myelination-related genes were associated with specific behavioral domains of autism (Setzu et al., 2006). Moreover, genome-wide transcriptional profiling techniques in combination with MRI and epigenetic analyses reveal that viral-like prenatal immune activation leads to myelinrelated epigenetic and transcriptional changes, which may lead to neurodevelopmental disorders like autism (Richetto et al., 2017). Recently, mutation of the chromatin remodeler protein CHD8, which is crucial for oligodendroglial development, was found to be associated with ASD (Setzu et al., 2004). Taken together, these research results suggest that white matter abnormalities may contribute to ASD pathogenesis, and targeting oligodendroglia may represent a new therapeutic strategy for ASD.
Endogenous remyelination usually occurs after demyelination, through the differentiation of OPCs and thus reproduction of myelin around the demyelinated axons (Back and Rosenberg, 2014; Safarzadeh et al., 2016). A successful remyelination is determined by the capability of OPCs to proliferate and differentiate into myelinating OLs, and these processes are also affected by the adenosine system (Fields, 2006). Accumulating evidence indicates that the adenosinergic signaling system is involved in immunity and inflammation of demyelinating diseases (Sebastiao and Ribeiro, 2009; Ginsberg et al., 2012), likely via $A R s\left(A_{1} R, A_{2 A} R, A_{2 B} R\right.$, and $\left.A_{3} R\right)$ on the surface of immune cells (Tsutsui et al., 2004). For instance, white matter injury (WMI) in premature newborn and embryos has been found to be closely related with adenosine (Johnston et al., 2001). Another typical example of such demyelinating diseases is MS, which is an autoimmune-mediated inflammatory disease characterized by multifocal demyelination that is associated with myelin destruction, oligodendroglial cell death, and axonal degeneration.

\section{Adenosine $\mathbf{A}_{\mathbf{1}}$ Receptor}

Clinical and experimental evidence indicates that $A_{1} R$ plays a role in the modulation of neuroinflammation (Si et al., 1996). A decreased expression of $A_{1} R$ in peripheral mononuclear cells and decreased adenosine levels in plasma were seen in patients with MS. In addition, expression of $\mathrm{A}_{1}$ Rs on $\mathrm{CD} 45^{+}$glial cells was decreased by $50 \%$ in MS patients and similar observations have been made in patients with other CNS diseases (Haselkorn et al., 2010). From animal studies it was shown that pharmacological activation of $A_{1} R$ by N6-cyclohexyladenosine (CHA) can induce remyelination and protect existing myelin in a rat model of optic chiasm demyelination. Further study revealed that this protective effect on myelinating cells is mediated by $A_{1} R$ by potentiating regeneration of endogenous neural progenitors (Asghari et al., 2013). Apparently, activation of $A_{1}$ Rs is an important inhibitory mechanism against neuroinflammation in MS and has also been observed to attenuate neuroinflammation and demyelination in EAEs animal models (Si et al., 1996; Yao et al., 2012). In accordance with these findings, studies have revealed that inactivation of $A_{1} R$ resulted in a progressive-relapsing form of EAE in $A_{1} R$ KO mice, with worsened demyelination and axonal injury, increased microglial proliferation, and enhanced expression of matrix metalloproteinase-12 (MMP-12), iNOS, as well as proinflammatory gene interleukin-1beta (IL-1 $\beta$ ) (Si et al., 1996). The modulation of microglial proliferation was also seen in pharmacological approaches, as both non-selective and selective $A_{1} R$ agonists attenuated the proliferation of rat microglia, and activation of $A_{1} R$ was shown as an endogenous inhibitor of the microglial response (Turner et al., 2002; Fogal et al., 2010). Therefore, the interplay between $A_{1} R$ and neuroinflammation is a reciprocal regulatory mechanism; namely, microglial $A_{1} R$ is downregulated during neuroinflammation in animal models of EAE and patients with MS (Hasko and Pacher, 2008), and the inactivation of $A_{1} R$, in turn, exacerbates EAE and MS progression. Thus, modulation of neuroinflammation by $A_{1} R$ manipulation may offer interesting therapeutic opportunities for MS and other demyelinating diseases (Yao et al., 2012). 
In developmental stages, however, adenosine acts via $A_{1}$ Rs and induced diffused WMI. Immature OLs express more $\mathrm{A}_{1}$ Rs compared with mature cells in vitro. Adenosine plays an important role in OL lineage progression by causing OL precursor cells to differentiate prematurely. $\mathrm{A}_{1} \mathrm{R}$ stimulation induces white matter loss and mediates hypoxia-induced ventriculomegaly (Mayne et al., 2001). Aiming at modulating this process may provide a novel strategy for WMI treatment (Sitkovsky et al., 2004).

\section{Adenosine $\mathrm{A}_{2 \mathrm{~A}}$ Receptor}

$\mathrm{A}_{2 \mathrm{~A}} \mathrm{R}$ also exerts significant anti-immune and anti-inflammatory actions on immune cells (Vincenzi et al., 2013; Ingwersen et al., 2016; Liu et al., 2018). In human studies, $A_{2 A} R s$ are up-regulated in $\mathrm{MS}$ patients and administration of the $\mathrm{A}_{2 \mathrm{~A}} \mathrm{R}$ agonist CGS-21680 can reduce lymphocyte proliferation of MS patients. This activation of $\mathrm{A}_{2 \mathrm{~A}} \mathrm{R}$ mediates a significant inhibition of tumor necrosis factor alpha (TNF- $\alpha$ ), IL-6, IL-1 $\beta$, IL-17, interferon gamma (IFN- $\gamma)$, and represses cell proliferation, expression of very late antigen (VLA)-4, and activation of NF-kB (Genovese et al., 2009). Further research has been conducted in animal models to assess the pattern of $\mathrm{A}_{2 \mathrm{~A}} \mathrm{R}$ expression in neuropathologically damaged tissue. $A_{2 A} R$ is seen to be expressed in infiltrating immune cells, as well as the surrounding endothelium; it is also up-regulated on $\mathrm{T}$ cells and macrophages/microglia in EAE lesions (Mills et al., 2008). Likewise, endothelial $\mathrm{A}_{2 \mathrm{~A}} \mathrm{R}$ is detected in demyelinated areas in MS brain samples (Mills et al., 2008). Moreover, $A_{2 A} R$ agonist CGS-21680 can ameliorate EAE neurological deficiencies in mice. In sum, $A_{2 A} R$ has been shown to have an overall influence in mediating BBB function in CNS demyelinating diseases (Matos et al., 2013).

Activation of $\mathrm{A}_{2 \mathrm{~A}} \mathrm{R}$ in vitro inhibits the migration of $\mathrm{CD}^{+}$ $\mathrm{T}$ cells, macrophages, and primary microglia, and suppresses macrophage/primary microglia-mediated phagocytosis of myelin. Along with this finding, $\mathrm{A}_{2 \mathrm{~A}} \mathrm{R}$-specific agonists have also been seen to inhibit myelin-specific $\mathrm{T}$ cell proliferation ex vivo and ameliorate EAE (Mills et al., 2008). $\mathrm{A}_{2 \mathrm{~A}} \mathrm{R}$ agonists suppressed in vivo primary mechanical injury and secondary inflammatory tissue damage after spinal cord injury; they can also reduce leukocyte recruitment and the activation of the JNK signaling pathway in oligodendroglia, thus protecting the spinal cord from injury-induced demyelination (Paterniti et al., 2011). In contrast, $A_{2 A} \mathrm{R} K O$ mice develop increased morbidity, exacerbated neurobehavioral deficits, and generally more severe EAE pathology than their WT littermates. $\mathrm{A}_{2 \mathrm{~A}} \mathrm{R}$ KO mice exhibit a severe phenotype of demyelination in EAE with enhanced infiltration of inflammatory cells in the spinal cord and cerebral cortex, accompanied by reduced expression of anti-inflammatory cytokines and increased expression of pro-inflammatory cytokines in the CNS and blood (Hasko and Pacher, 2008). However, studies also demonstrated that there is a dual role of $\mathrm{A}_{2 \mathrm{~A}} \mathrm{R}$ in autoimmune neuroinflammation; for instance, $\mathrm{A}_{2 \mathrm{~A}} \mathrm{R}$ specific agonists inhibited the proliferation of myelin-specific T cell ex vivo and ameliorated EAE, whereas application of the same agonist after the onset of disease exacerbated progression of non-remitting EAE. This suggests that activation of $\mathrm{A}_{2 \mathrm{~A}} \mathrm{R}$ exerts complex effects on chronic autoimmune neurodegeneration (Wei et al., 2013). The paradoxical effects of $A_{2 A} R$ may be dependent on pathophysiological conditions; further studies are needed to clarify the manipulatory role of $\mathrm{A}_{2 \mathrm{~A}} \mathrm{R}$ on demyelinating disorders as well as the potential shifting of the predominant role of $\mathrm{A}_{1} \mathrm{R}$ and $\mathrm{A}_{2 \mathrm{~A}} \mathrm{R}$ in the pathogenesis of demyelination.

In developmental models, adenosine signaling pathway acts via $A_{2 A} R$ to inhibit OPC differentiation (Coppi et al., 2013). Increased nitric oxide release by microglia, up-regulated neuronal glutamate release, and decreased glutamate uptake by astrocytes are all results of $\mathrm{A}_{2 \mathrm{~A}} \mathrm{R}$ activation, and leads to aggravated excitotoxicity (Cook, 1990). Blockade of $\mathrm{A}_{2 \mathrm{~A}} \mathrm{R}$, on the other hand, has been revealed to have a negative effect on demyelination in the spinal cord injury model (Masino et al., 2011).

\section{Adenosine $A_{2 B}$ and $A_{3}$ Receptors}

The $A_{2 B} R$ is a relatively low-affinity adenosine receptor compared to $A_{1} R$ and $A_{2 A} R$; in fact, the activation of $A_{2 B} R$ requires a pathologically enhanced level of adenosine (Fredholm et al., 2005a; Chen et al., 2013). A clinical study revealed upregulated $\mathrm{A}_{2 \mathrm{~B}} \mathrm{R}$ in the peripheral leukocytes of MS patients; this is in line with findings which showed increased $\mathrm{A}_{2 \mathrm{~B}}$ Rs in lymphoid tissues of EAE mice (Lazarus et al., 2011). Pharmacological blockade of $\mathrm{A}_{2 \mathrm{~B}} \mathrm{R}$ (via $\mathrm{A}_{2 \mathrm{~B}} \mathrm{R}$ antagonists MRS-1754 and CVT6883 ) relieved the symptoms and pathological changes of EAE, accompanied by a suppression of IL- 6 production and Th17 cell differentiation. A promising work from Gonzalez-Fernandez et al. (2014) demonstrated that activation of $\mathrm{A}_{3} \mathrm{R}$ may contribute to oligodendroglial cell death in optic nerve and white matter ischemic damage. However, further investigations are required to fully understand the effects of $\mathrm{A}_{2 \mathrm{~B}} \mathrm{R}$ and $\mathrm{A}_{3} \mathrm{R}$ in the myelination and demyelination processing.

\section{ADENOSINE ACTIONS IN AUTISM}

The study of adenosine in regards to autism has been around for decades (Masino et al., 2013); however, only within the last 10 years have multiple lines of research revealed the important role of adenosine and ARs in ASD. Due to findings that adenosine action affects many various aspects of ASDs, such as neuronal activity, sleep and seizures, cognition, and anxiety, the adenosine signaling pathway may be primed to be a potential therapeutic target for ASD.

\section{Adenosine and Its Metabolism in ASD}

A patient study from Masino et al. (2009) using a customized parent-based questionnaire indicated an observable relationship between activities that were predicted to increase adenosine levels in the brain and parental observations of relieved behavioral manifestations of ASD. Their results suggest, in general, that increased adenosine signaling activity can benefit sleep disorders, seizures, and social and behavioral dysfunction in ASD (Stubbs et al., 1982; Shen et al., 2008). Augmentation of adenosine signaling activity may serve as a novel therapeutic strategy for ASD with multiple potential beneficial effects in alleviating core symptoms and several comorbidities of ASD (Bottini et al., 2001). 
However, no direct evidence of dysregulated adenosine in the brain has been tested with respect to the manifestations of ASD (Hettinger et al., 2008). Adenosine metabolic enzymes were also found to have links to ASD. A reduced activity of ADA was reported in the sera of autistic children (Freitag et al., 2010), and a low-activity polymorphism (Asp8Asn) of ADA gene was found to be significantly associated with ASD patients (Ansari et al., 2017a; Amodeo et al., 2018). The above lines of research suggest that reduced $\mathrm{ADA}$ activity may be a risk factor for the development of ASD.

\section{Adenosine Receptors and ASD}

The $\mathrm{A}_{2 \mathrm{~A}} \mathrm{Rs}$ are found expressed predominantly in the caudate nucleus, where they exert their influence in ASD pathology (Ahmad et al., 2017a). Genetic studies reveal that one of the polymorphisms of $A_{2 \mathrm{~A}} R$ gene, rs2236624-CC, has a nominal association with ASD and three others, rs3761422, rs5751876 and rs35320474, and influences phenotypic variability in ASD symptoms (Ahmad et al., 2017a). Interestingly, the $\mathrm{A}_{2 \mathrm{~A}} \mathrm{R}$ gene is located on chromosome 22q11.23, and large 22q11.2 duplications and deletions were observed in individuals with ASD; this correlation suggests a possible role of $\mathrm{A}_{2 \mathrm{~A}} \mathrm{R}$ variants in mediating phenotypic expression in ASD (Ahmad et al., 2017a).

Repetitive behaviors and restricted interests are commonly related to neurodevelopmental disorders which are diagnostic for ASD. As a means of exploring these phenotypes, BTBR $\mathrm{T}^{+}$Itpr3tf/J (aka BTBR) mice can be utilized as an animal model of idiopathic autism due to their strong and consistent autism-relevant behaviors (Ahmad et al., 2017b; Ansari et al., 2017b). Studies showed that $\mathrm{A}_{2 \mathrm{~A}} \mathrm{R}$ agonism via the adenosine analog CGS-21680 caused a reduction of repetitive and inflexible behaviors in these $\mathrm{BTBR}$ mice, whereas $\mathrm{A}_{2 \mathrm{~A}} \mathrm{R}$ antagonist SCH-58261 treatment exacerbated repetitive behaviors. This antagonism was also seen to cause a decreased expression of IL-27 and IkB- $\alpha$ and an increased expression of NF-kB p65 and toll-like receptors, TLR2, TLR3, and TLR4 in the brain (Tanimura et al., 2010; Campbell et al., 2013; Lopez-Cruz et al., 2017). Correspondingly, other pharmacological studies have shown that activation of $\mathrm{A}_{1} \mathrm{R}$ and $\mathrm{A}_{2 \mathrm{~A}} \mathrm{R}$ via co-administration of $\mathrm{A}_{2 \mathrm{~A}} \mathrm{R}$ agonist CGS-21680 and $\mathrm{A}_{1} \mathrm{R}$ agonist CPA attenuates stereotypy (repetitive behaviors) in a second animal model of ASD in a dose-dependent manner (Zhu et al., 2011). $\mathrm{A}_{2 \mathrm{~A}} \mathrm{R}$ inactivation also affects social behaviors and anxiety in the autism spectrum; $\mathrm{A}_{2 \mathrm{~A}} \mathrm{R}$ knockout mice show an anxiety profile, higher levels of sociability, and a reduced sensitivity to social novelty (Matute et al., 2001). Pharmacological manipulation of $\mathrm{A}_{2 \mathrm{~A}} \mathrm{R}$ can conversely potentiate motivation to work. Together, these studies support the notion that augmentation of AR activities in the CNS could be a promising therapeutic strategy for ASD.

In addition, a third player, $A_{3} R$, was shown to have two rare coding variants (Leu90Val and Val171Ile) in a genetics study using four single-nucleotide polymorphisms (SNPs) representing common haplotypes of 958 families with autism. It was revealed that these variations were found at an increased rate in ASD cases (Alberdi et al., 2006). Further in vitro analysis revealed that these same coding variants, Val90- $\mathrm{A}_{3} \mathrm{R}$ and Ile171- $\mathrm{A}_{3} \mathrm{R}$, link to an elevated 5-HT re-uptake activity which responds differently to agonism of the 5-HT transporter. This suggests that these

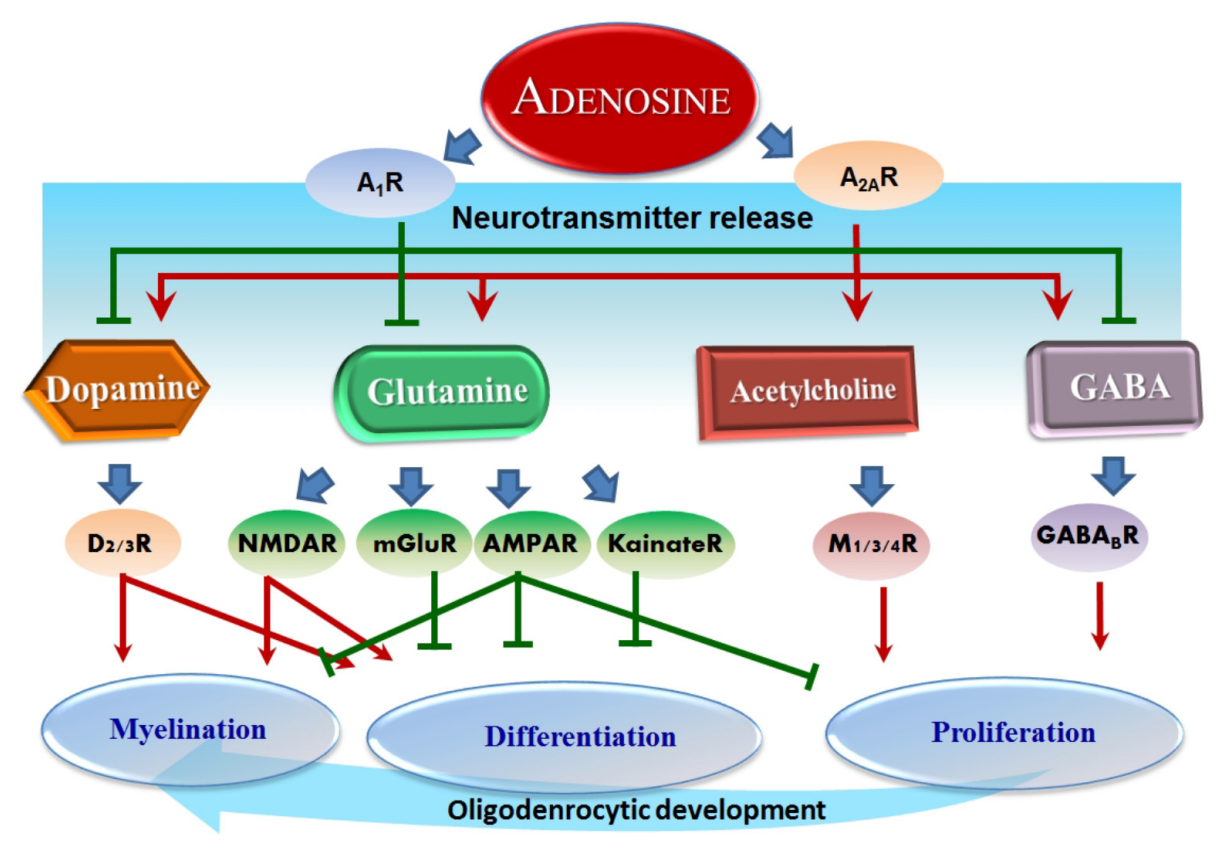

FIGURE 2 | Adenosine-modulated neurotransmitters and their effects on OLs. Overview of adenosine effect on neurotransmitters: adenosine inhibits dopamine, glutamine, and GABA through $A_{1} R$, whereas $A_{2 A} R$ serves to conversely promote dopamine, glutamine, acetylcholine, and GABA. These neurotransmitters successively regulate further downstream receptors and ultimately several essential processes in oligodendrocytic development, such as proliferation, differentiation, and myelination. Red arrows represent a stimulation effect; Green bars represent an inhibition effect; Blue arrows show the directionality of effects. 
hyperfunctional coding variants of $\mathrm{A}_{3} \mathrm{R}$ may have an impact on ASD risk (Alberdi et al., 2006; Chez et al., 2007).

\section{ADENOSINE AND RELATED NEUROTRANSMITTERS IN ASD}

Adenosine-related neurotransmitters, such as glutamate, dopamine, histamine, and others have all taken part in the initiation and progression of ASD. Under pathological conditions, glutamate can also damage white matter via an over-activation of NMDAR, which is seen in ischemia, anoxia, infection, and MS (Owley et al., 2006). Likewise, glutamate can also cause the damage and death of OLs via activating AMPAR or kainate receptors, which in turn detrimentally increases $\mathrm{Ca}^{++}$permeability (Karadottir and Attwell, 2007). In addition, glutamate can also activate kainate receptor-linked microglia/macrophage action to cause OL damage (Hellings et al., 2017). However, inhibition of AMPAR or kainate receptors alone does not exert an effect on OLs or myelination. Together, these data suggest that glutamate facilitates migration but inhibits the proliferation of OPCs, which is similar to adenosine-mediated effects on oligodendroglial lineage cells. This suggests that the effect of glutamate in disease may be caused by adenosine. In some ASD individuals, glutamate levels were found to be abnormally high (Paval, 2017). Glutamate antagonists, such as amantadine and memantine, have been shown to be effective in ASD treatment, by improving memory, hyperactivity, irritability, language, social behavior, and self-stimulatory behavior (Paval, 2017; Lee et al., 2018).

Dopamine has a fundamental role in the brain and its role in ASD has already been thoroughly studied (Seeman, 2010; Mei et al., 2016a). Moreover, it has been shown that using antagonists for dopamine $D_{1}$ receptors in mice revealed significant deficits in sociability and repetitive behaviors related to ASD. Small interfering RNA (siRNA)-mediated inhibition of dopamine $\mathrm{D}_{2}$ receptors in the dorsal striatum replicated ASD-like phenotypes (Mei et al., 2016b). Dopaminergic system deficits have been closely related to behavior skills such as analyzing, planning and prioritizing (Matson et al., 2011). Consistent with this, children with ASD revealed deficits in working memory and flexibility. Dopamine has a close relationship with social behavior, attentional skills, and perception, which are all related to ASD (Mei et al., 2016a). Recently, it was found that muscarinic M1 receptors negatively regulate OPC differentiation and their ablation can accelerate remyelination (Mei et al., 2016a). Notably, oligodendroglial development and myelination are complex programs under the control of multiple neurotransmitters. For instance, it was found that quetiapine, an antagonist

\section{REFERENCES}

Abiraman, K., Pol, S. U., O’Bara, M. A., Chen, G. D., Khaku, Z. M., Wang, J., et al. (2015). Anti-muscarinic adjunct therapy accelerates functional human oligodendrocyte repair. J. Neurosci. 35, 3676-3688. doi: 10.1523/JNEUROSCI. 3510- 14.2015

Ahmad, S. F., Ansari, M. A., Nadeem, A., Bakheet, S. A., Al-Ayadhi, L. Y., and Attia, S. M. (2017a). Toll-like receptors, NF-kappaB, and IL-27 mediate for multiple neurotransmitters including dopamine, muscarine, and opioids, promoted OL differentiation and remyelination (Mei et al., 2016b), demonstrating that quetiapine may be a promising drug to be tested in future clinical trials. These facts reveal the importance of neurotransmitters in ASD and that targeting dopamine and/or glutamate signaling pathway effects on myelination is an effective strategy for ASD treatment. Currently, however, only two atypical antipsychotic drugs, risperidone and aripiprazole, are FDA-approved as clinically effective in improving ASD behavioral symptoms (Matson et al., 2011). Therefore, it may be a promising strategy to treat ASD by regulating adenosine, which will in turn affect the related neurotransmitters (Figure 2).

\section{CONCLUDING REMARKS}

Increased evidence from clinical and basic research suggests a relationship between the adenosine signaling system and ASD. The broad actions of the adenosinergic system on neuroprotection, neuroinflammation, modulation of neurotransmissions, and regulation of glial function are involved in the core behavioral symptoms in ASD, irrespective of cognitive function. Therefore, adenosine-based strategies, through manipulating adenosine signaling pathways and affecting oligodendrocyte activities, may be utilized to therapeutically target core symptoms and comorbidities of ASD. Although adenosine's effect is complex and pleiotropic, its effect on myelination can work through multiple neurotransmitterinduced pathways and improve behavior deficits in ASD, suggesting that this strategy is effective. However, focused studies on adenosine, oligodendroglia, and myelination are urgently needed to fully uncover the role of the adenosine system in ASD. While multiple adenosine receptor agonists are in clinical trials, therapeutic augmentation of adenosinergic signaling is ready to be tested for diverse potential benefits against multiple comorbidities on the autism spectrum.

\section{AUTHOR CONTRIBUTIONS}

$\mathrm{H}-\mathrm{YS}$ and $\mathrm{NH}$ wrote the manuscript. JR and LX revised the manuscript. H-YS and LX designed the manuscript.

\section{FUNDING}

This work was supported by the National Natural Science Foundation of China (NSCF31671117).

adenosine A2A receptor signaling in BTBR $\mathrm{T}(+)$ Itpr3(tf)/J mice. Prog. Neuropsychopharmacol. Biol. Psychiatry 79(Pt B), 184-191. doi: 10.1016/j. pnpbp.2017.06.034

Ahmad, S. F., Ansari, M. A., Nadeem, A., Bakheet, S. A., Almutairi, M. M., and Attia, S. M. (2017b). Adenosine A2A receptor signaling affects IL-21/IL-22 cytokines and GATA3/T-bet transcription factor expression in CD4(+) T cells from a BTBR T(+) Itpr3tf/J mouse model of autism. J. Neuroimmunol. 311, 59-67. doi: 10.1016/j.jneuroim.2017.08.002 
Alberdi, E., Sanchez-Gomez, M. V., Torre, I., Domercq, M., Perez-Samartin, A., Perez-Cerda, F., et al. (2006). Activation of kainate receptors sensitizes oligodendrocytes to complement attack. J. Neurosci. 26, 3220-3228. doi: 10. 1523/JNEUROSCI.3780-05.2006

Amodeo, D. A., Cuevas, L., Dunn, J. T., Sweeney, J. A., and Ragozzino, M. E. (2018). The adenosine A2A receptor agonist, CGS 21680, attenuates a probabilistic reversal learning deficit and elevated grooming behavior in BTBR mice. Autism Res. 11, 223-233. doi: 10.1002/aur.1901

Ansari, M. A., Attia, S. M., Nadeem, A., Bakheet, S. A., Raish, M., Khan, T. H., et al. (2017a). Activation of adenosine A2A receptor signaling regulates the expression of cytokines associated with immunologic dysfunction in BTBR T(+) Itpr3(tf)/J mice. Mol. Cell. Neurosci. 82, 76-87. doi: 10.1016/j.mcn.2017. 04.012

Ansari, M. A., Nadeem, A., Attia, S. M., Bakheet, S. A., Raish, M., and Ahmad, S. F. (2017b). Adenosine A2A receptor modulates neuroimmune function through Th17/retinoid-related orphan receptor gamma t (RORgammat) signaling in a BTBR T(+) Itpr3(tf)/J mouse model of autism. Cell. Signal. 36, 14-24. doi: 10.1016/j.cellsig.2017.04.014

Asghari, A. A., Azarnia, M., Mirnajafi-Zadeh, J., and Javan, M. (2013). Adenosine A1 receptor agonist, N6-cyclohexyladenosine, protects myelin and induces remyelination in an experimental model of rat optic chiasm demyelination; electrophysiological and histopathological studies. J. Neurol. Sci. 325, 22-28. doi: 10.1016/j.jns.2012.11.008

Back, S. A., and Rosenberg, P. A. (2014). Pathophysiology of glia in perinatal white matter injury. Glia 62, 1790-1815. doi: 10.1002/glia.22658

Baldwin, S. A., Beal, P. R., Yao, S. Y., King, A. E., Cass, C. E., and Young, J. D. (2004). The equilibrative nucleoside transporter family, SLC29. Pflugers Arch. 447, 735-743. doi: 10.1007/s00424-003-1103-2

Barnea-Goraly, N., Kwon, H., Menon, V., Eliez, S., Lotspeich, L., and Reiss, A. L. (2004). White matter structure in autism: preliminary evidence from diffusion tensor imaging. Biol. Psychiatry 55, 323-326. doi: 10.1016/j.biopsych.2003.10. 022

Belachew, S., Rogister, B., Rigo, J. M., Malgrange, B., and Moonen, G. (1999). Neurotransmitter-mediated regulation of CNS myelination: a review. Acta Neurol. Belg. 99, 21-31.

Belmonte, M. K., Cook, E. H. Jr., Anderson, G. M., Rubenstein, J. L., Greenough, W. T., Beckel-Mitchener, A., et al. (2004). Autism as a disorder of neural information processing: directions for research and targets for therapy. Mol. Psychiatry 9, 646-663. doi: 10.1038/sj.mp.4001499

Boison, D., Chen, J. F., and Fredholm, B. B. (2010). Adenosine signalling and function in glial cells. Cell Death Differ. 17, 1071-1082. doi: 10.1038/cdd.2009. 131

Boison, D., and Shen, H. Y. (2010). Adenosine kinase is a new therapeutic target to prevent ischemic neuronal death. Open Drug Discov. J. 2, $108-118$.

Bolton, P. F., Roobol, M., Allsopp, L., and Pickles, A. (2001). Association between idiopathic infantile macrocephaly and autism spectrum disorders. Lancet 358, 726-727. doi: 10.1016/S0140-6736(01)05903-7

Bongarzone, E. R., Howard, S. G., Schonmann, V., and Campagnoni, A. T. (1998). Identification of the dopamine D3 receptor in oligodendrocyte precursors: potential role in regulating differentiation and myelin formation. J. Neurosci. 18, 5344-5353. doi: 10.1523/JNEUROSCI.18-14-05344.1998

Borea, P. A., Gessi, S., Merighi, S., and Varani, K. (2016). Adenosine as a multisignalling guardian angel in human diseases: When, Where and How Does it Exert its Protective Effects? Trends Pharmacol. Sci. 37, 419-434. doi: 10.1016/j. tips.2016.02.006

Bottini, N., De Luca, D., Saccucci, P., Fiumara, A., Elia, M., Porfirio, M. C., et al. (2001). Autism: evidence of association with adenosine deaminase genetic polymorphism. Neurogenetics 3, 111-113. doi: 10.1007/s100480000104

Broch, O. J., and Ueland, P. M. (1980). Regional and subcellular distribution of S-adenosylhomocysteine hydrolase in the adult rat brain. J. Neurochem. 35, 484-488. doi: 10.1111/j.1471-4159.1980.tb06291.x

Burnstock, G., Fredholm, B. B., and Verkhratsky, A. (2011a). Adenosine and ATP receptors in the brain. Curr. Top. Med. Chem. 11, 973-1011. doi: 10.2174/ 156802611795347627

Burnstock, G., Krugel, U., Abbracchio, M. P., and Illes, P. (2011b). Purinergic signalling: from normal behaviour to pathological brain function. Prog. Neurobiol. 95, 229-274. doi: 10.1016/j.pneurobio.2011.08.006
Campbell, N. G., Zhu, C. B., Lindler, K. M., Yaspan, B. L., Kistner-Griffin, E., Consortium, N. A., et al. (2013). Rare coding variants of the adenosine A3 receptor are increased in autism: on the trail of the serotonin transporter regulome. Mol. Autism 4:28. doi: 10.1186/2040-2392-4-28

Carmody, D. P., and Lewis, M. (2010). Regional white matter development in children with autism spectrum disorders. Dev. Psychobiol. 52, 755-763. doi: 10.1002/dev.20471

Cass, C. E., Young, J. D., Baldwin, S. A., Cabrita, M. A., Graham, K. A., Griffiths, M., et al. (1999). Nucleoside transporters of mammalian cells. Pharm. Biotechnol. 12, 313-352. doi: 10.1007/0-306-46812-3_12

Chen, J. A., Penagarikano, O., Belgard, T. G., Swarup, V., and Geschwind, D. H. (2015). The emerging picture of autism spectrum disorder: genetics and pathology. Annu. Rev. Pathol. 10, 111-144. doi: 10.1146/annurev-pathol012414-040405

Chen, J. F., Eltzschig, H. K., and Fredholm, B. B. (2013). Adenosine receptors as drug targets-what are the challenges? Nat. Rev. Drug Discov. 12, 265-286. doi: $10.1038 / \mathrm{nrd} 3955$

Chez, M. G., Burton, Q., Dowling, T., Chang, M., Khanna, P., and Kramer, C. (2007). Memantine as adjunctive therapy in children diagnosed with autistic spectrum disorders: an observation of initial clinical response and maintenance tolerability. J. Child Neurol. 22, 574-579. doi: 10.1177/0883073807302611

Cook, E. H. (1990). Autism: review of neurochemical investigation. Synapse 6, 292-308. doi: 10.1002/syn.890060309

Coppi, E., Cellai, L., Maraula, G., Pugliese, A. M., and Pedata, F. (2013). Adenosine $\mathrm{A}(2) \mathrm{A}$ receptors inhibit delayed rectifier potassium currents and cell differentiation in primary purified oligodendrocyte cultures. Neuropharmacology 73, 301-310. doi: 10.1016/j.neuropharm.2013.05.035

Courchesne, E. (2004). Brain development in autism: early overgrowth followed by premature arrest of growth. Ment. Retard. Dev. Disabil. Res. Rev. 10, 106-111. doi: $10.1002 / \mathrm{mrdd} .20020$

Cunha, R. A. (2001). Adenosine as a neuromodulator and as a homeostatic regulator in the nervous system: different roles, different sources and different receptors. Neurochem. Int. 38, 107-125. doi: 10.1016/S0197-0186(00) 00034-6

Cunha, R. A., Constantino, M. C., Sebastiao, A. M., and Ribeiro, J. A. (1995a). Modification of $\mathrm{A} 1$ and $\mathrm{A} 2 \mathrm{a}$ adenosine receptor binding in aged striatum, hippocampus and cortex of the rat. Neuroreport 6, 1583-1588.

Cunha, R. A., Johansson, B., Fredholm, B. B., Ribeiro, J. A., and Sebastiao, A. M. (1995b). Adenosine A2A receptors stimulate acetylcholine release from nerve terminals of the rat hippocampus. Neurosci. Lett. 196, 41-44.

Dare, E., Schulte, G., Karovic, O., Hammarberg, C., and Fredholm, B. B. (2007). Modulation of glial cell functions by adenosine receptors. Physiol. Behav. 92, 15-20. doi: 10.1016/j.physbeh.2007.05.031

Deoni, S. C., Zinkstok, J. R., Daly, E., Ecker, C., Williams, S. C., and Murphy, D. G. (2015). White-matter relaxation time and myelin water fraction differences in young adults with autism. Psychol. Med. 45, 795-805. doi: 10.1017/ S0033291714001858

Dixon, A. K., Widdowson, L., and Richardson, P. J. (1997). Desensitisation of the adenosine A1 receptor by the A2A receptor in the rat striatum. J. Neurochem. 69, 315-321. doi: 10.1046/j.1471-4159.1997.69010315.x

Dunwiddie, T. V., and Masino, S. A. (2001). The role and regulation of adenosine in the central nervous system. Annu. Rev. Neurosci. 24, 31-55. doi: 10.1146/ annurev.neuro.24.1.31

Ferre, S., Ciruela, F., Canals, M., Marcellino, D., Burgueno, J., Casado, V., et al. (2004). Adenosine A2A-dopamine D2 receptor-receptor heteromers. Targets for neuro-psychiatric disorders. Parkinsonism Relat. Disord. 10, 265-271. doi: 10.1016/j.parkreldis.2004.02.014

Ferre, S., Herrera-Marschitz, M., Grabowska-Anden, M., Ungerstedt, U., Casas, M., and Anden, N. E. (1991). Postsynaptic dopamine/adenosine interaction: I. Adenosine analogues inhibit dopamine D2-mediated behaviour in short-term reserpinized mice. Eur. J. Pharmacol. 192, 25-30. doi: 10.1016/0014-2999(91) 90064-W

Fields, R. D. (2006). Nerve impulses regulate myelination through purinergic signalling. Novartis Found. Symp. 276, 148-158; discussion 158-161, 233-237, 275-281. doi: 10.1002/9780470032244.ch12

Fogal, B., McClaskey, C., Yan, S., Yan, H., and Rivkees, S. A. (2010). Diazoxide promotes oligodendrocyte precursor cell proliferation and myelination. PLoS One 5:e10906. doi: 10.1371/journal.pone.0010906 
Fombonne, E., Roge, B., Claverie, J., Courty, S., and Fremolle, J. (1999). Microcephaly and macrocephaly in autism. J. Autism Dev. Disord. 29, 113-119. doi: 10.1023/A:1023036509476

Fredholm, B. B., Chen, J. F., Cunha, R. A., Svenningsson, P., and Vaugeois, J. M. (2005a). Adenosine and brain function. Int. Rev. Neurobiol. 63, 191-270. doi: 10.1016/S0074-7742(05)63007-3

Fredholm, B. B., Chen, J. F., Masino, S. A., and Vaugeois, J. M. (2005b). Actions of adenosine at its receptors in the CNS: insights from knockouts and drugs. Annu. Rev. Pharmacol. Toxicol. 45, 385-412.

Fredholm, B. B., and Dunwiddie, T. V. (1988). How does adenosine inhibit transmitter release? Trends Pharmacol. Sci. 9, 130-134. doi: 10.1016/01656147(88)90194-0

Freitag, C. M., Agelopoulos, K., Huy, E., Rothermundt, M., Krakowitzky, P., Meyer, J., et al. (2010). Adenosine A(2A) receptor gene (ADORA2A) variants may increase autistic symptoms and anxiety in autism spectrum disorder. Eur. Child Adolesc. Psychiatry 19, 67-74. doi: 10.1007/s00787-009-0043-6

Genovese, T., Melani, A., Esposito, E., Mazzon, E., Di Paola, R., Bramanti, P., et al. (2009). The selective adenosine A2A receptor agonist CGS 21680 reduces JNK MAPK activation in oligodendrocytes in injured spinal cord. Shock 32, 578-585. doi: 10.1097/SHK.0b013e3181a20792

Ginsberg, M. R., Rubin, R. A., Falcone, T., Ting, A. H., and Natowicz, M. R. (2012). Brain transcriptional and epigenetic associations with autism. PLoS One 7:e44736. doi: 10.1371/journal.pone.0044736

Gonzalez-Fernandez, E., Sanchez-Gomez, M. V., Perez-Samartin, A., Arellano, R. O., and Matute, C. (2014). A3 Adenosine receptors mediate oligodendrocyte death and ischemic damage to optic nerve. Glia 62, 199-216. doi: 10.1002/glia. 22599

Gorter, J. A., van Vliet, E. A., Lopes da Silva, F. H., Isom, L. L., and Aronica, E. (2002). Sodium channel betal-subunit expression is increased in reactive astrocytes in a rat model for mesial temporal lobe epilepsy. Eur. J. Neurosci. 16, 360-364. doi: 10.1046/j.1460-9568.2002.02078.x

Gray, J. H., Owen, R. P., and Giacomini, K. M. (2004). The concentrative nucleoside transporter family, SLC28. Pflugers Arch. 447, 728-734. doi: 10.1007/s00424003-1107-y

Gu, J. G., Foga, I. O., Parkinson, F. E., and Geiger, J. D. (1995). Involvement of bidirectional adenosine transporters in the release of $\mathrm{L}-(3 \mathrm{H})$ adenosine from rat brain synaptosomal preparations. J. Neurochem. 64, 2105-2110. doi: 10.1046/j. 1471-4159.1995.64052105.x

Hamilton, N. B., Clarke, L. E., Arancibia-Carcamo, I. L., Kougioumtzidou, E., Matthey, M., Karadottir, R., et al. (2017). Endogenous GABA controls oligodendrocyte lineage cell number, myelination, and CNS internode length. Glia 65, 309-321. doi: 10.1002/glia.23093

Haselkorn, M. L., Shellington, D. K., Jackson, E. K., Vagni, V. A., JaneskoFeldman, K., Dubey, R. K., et al. (2010). Adenosine A1 receptor activation as a brake on the microglial response after experimental traumatic brain injury in mice. J. Neurotrauma 27, 901-910. doi: 10.1089/neu.2009.1075

Hasko, G., and Pacher, P. (2008). A2A receptors in inflammation and injury: lessons learned from transgenic animals. J. Leukoc. Biol. 83, 447-455. doi: $10.1189 / \mathrm{jlb} .0607359$

Hazlett, H. C., Poe, M., Gerig, G., Smith, R. G., Provenzale, J., Ross, A., et al. (2005). Magnetic resonance imaging and head circumference study of brain size in autism: birth through age 2 years. Arch. Gen. Psychiatry 62, 1366-1376. doi: $10.1001 /$ archpsyc.62.12.1366

Hellings, J. A., Arnold, L. E., and Han, J. C. (2017). Dopamine antagonists for treatment resistance in autism spectrum disorders: review and focus on BDNF stimulators loxapine and amitriptyline. Expert Opin. Pharmacother. 18, 581-588. doi: 10.1080/14656566.2017.1308483

Hettinger, J. A., Liu, X., and Holden, J. J. (2008). The G22A polymorphism of the ADA gene and susceptibility to autism spectrum disorders. J. Autism Dev. Disord. 38, 14-19. doi: 10.1007/s10803-006-0354-0

Imamura, O., Arai, M., Dateki, M., Ogata, T., Uchida, R., Tomoda, H., et al. (2015). Nicotinic acetylcholine receptors mediate donepezil-induced oligodendrocyte differentiation. J. Neurochem. 135, 1086-1098. doi: 10.1111/jnc.13294

Ingwersen, J., Wingerath, B., Graf, J., Lepka, K., Hofrichter, M., Schroter, F., et al. (2016). Dual roles of the adenosine A2a receptor in autoimmune neuroinflammation. J. Neuroinflammation 13:48. doi: 10.1186/s12974-016$0512-\mathrm{z}$
Johnston, J. B., Silva, C., Gonzalez, G., Holden, J., Warren, K. G., Metz, L. M., et al. (2001). Diminished adenosine A1 receptor expression on macrophages in brain and blood of patients with multiple sclerosis. Ann. Neurol. 49, 650-658. doi: 10.1002/ana.1007

Karadottir, R., and Attwell, D. (2007). Neurotransmitter receptors in the life and death of oligodendrocytes. Neuroscience 145, 1426-1438. doi: 10.1016/j. neuroscience.2006.08.070

Karadottir, R., Cavelier, P., Bergersen, L. H., and Attwell, D. (2005). NMDA receptors are expressed in oligodendrocytes and activated in ischaemia. Nature 438, 1162-1166. doi: 10.1038/nature04302

Kiese, K., Jablonski, J., Boison, D., and Kobow, K. (2016). Dynamic regulation of the adenosine kinase gene during early postnatal brain development and maturation. Front. Mol. Neurosci. 9:99. doi: 10.3389/fnmol.2016.00099

Kirk, I. P., and Richardson, P. J. (1994). Adenosine A2a receptor-mediated modulation of striatal $[3 \mathrm{H}] \mathrm{GABA}$ and $[3 \mathrm{H}]$ acetylcholine release. J. Neurochem. 62, 960-966. doi: 10.1046/j.1471-4159.1994.62030960.x

Kirkpatrick, K. A., and Richardson, P. J. (1993). Adenosine receptor-mediated modulation of acetylcholine release from rat striatal synaptosomes. $\mathrm{Br} . \mathrm{J}$. Pharmacol. 110, 949-954. doi: 10.1111/j.1476-5381.1993.tb13905.x

Kolodziejczyk, K., Hamilton, N. B., Wade, A., Karadottir, R., and Attwell, D. (2009). The effect of $\mathrm{N}$-acetyl-aspartyl-glutamate and N-acetyl-aspartate on white matter oligodendrocytes. Brain 132(Pt 6), 1496-1508. doi: 10.1093/brain/ awp087

Latini, S., Pazzagli, M., Pepeu, G., and Pedata, F. (1996). A2 adenosine receptors: their presence and neuromodulatory role in the central nervous system. Gen. Pharmacol. 27, 925-933. doi: 10.1016/0306-3623(96)00044-4

Latini, S., and Pedata, F. (2001). Adenosine in the central nervous system: release mechanisms and extracellular concentrations. J. Neurochem. 79, 463-484. doi: 10.1046/j.1471-4159.2001.00607.x

Lazarus, M., Shen, H. Y., Cherasse, Y., Qu, W. M., Huang, Z. L., Bass, C., et al. (2011). Arousal effect of caffeine depends on adenosine A2A receptors in the shell of the nucleus accumbens. J. Neurosci. 31, 10067-10075. doi: 10.1523/ JNEUROSCI.6730-10.2011

Lee, Y., Kim, H., Kim, J. E., Park, J. Y., Choi, J., Lee, J. E., et al. (2018). Excessive D1 dopamine receptor activation in the dorsal striatum promotes autistic-like behaviors. Mol. Neurobiol. 55, 5658-5671. doi: 10.1007/s12035-017-0770-5

Lindahl, J. S., Kjellsen, B. R., Tigert, J., and Miskimins, R. (2008). In utero PCP exposure alters oligodendrocyte differentiation and myelination in developing rat frontal cortex. Brain Res. 1234, 137-147. doi: 10.1016/j.brainres.2008.06.126

Liu, Y., Alahiri, M., Ulloa, B., Xie, B., and Sadiq, S. A. (2018). Adenosine A2A receptor agonist ameliorates EAE and correlates with Th1 cytokine-induced blood brain barrier dysfunction via suppression of MLCK signaling pathway. Immun. Inflamm. Dis. 6, 72-80. doi: 10.1002/iid3.187

Lopes, L. V., Cunha, R. A., and Ribeiro, J. A. (1999). Cross talk between A(1) and $\mathrm{A}(2 \mathrm{~A})$ adenosine receptors in the hippocampus and cortex of young adult and old rats. J. Neurophysiol. 82, 3196-3203. doi: 10.1152/jn.1999.82.6.3196

Lopez-Cruz, L., Carbo-Gas, M., Pardo, M., Bayarri, P., Valverde, O., Ledent, C., et al. (2017). Adenosine A2A receptor deletion affects social behaviors and anxiety in mice: Involvement of anterior cingulate cortex and amygdala. Behav. Brain Res. 321, 8-17. doi: 10.1016/j.bbr.2016.12.020

Masino, S. A., Kawamura, M. Jr., Cote, J. L., Williams, R. B., and Ruskin, D. N. (2013). Adenosine and autism: a spectrum of opportunities. Neuropharmacology 68, 116-121. doi: 10.1016/j.neuropharm.2012.08.013

Masino, S. A., Kawamura, M. Jr., Plotkin, L. M., Svedova, J., DiMario, F. J. Jr., and Eigsti, I. M. (2011). The relationship between the neuromodulator adenosine and behavioral symptoms of autism. Neurosci. Lett. 500, 1-5. doi: 10.1016/j. neulet.2011.06.007

Masino, S. A., Kawamura, M., Wasser, C. A., Pomeroy, L. T., and Ruskin, D. N. (2009). Adenosine, ketogenic diet and epilepsy: the emerging therapeutic relationship between metabolism and brain activity. Curr. Neuropharmacol. 7 , 257-268. doi: 10.2174/157015909789152164

Matos, M., Augusto, E., Agostinho, P., Cunha, R. A., and Chen, J. F. (2013). Antagonistic interaction between adenosine $\mathrm{A} 2 \mathrm{~A}$ receptors and $\mathrm{Na}+\mathrm{K}+-$ ATPase-alpha2 controlling glutamate uptake in astrocytes. J. Neurosci. 33, 18492-18502. doi: 10.1523/JNEUROSCI.1828-13.2013

Matos, M., Shen, H. Y., Augusto, E., Wang, Y., Wei, C. J., Wang, Y. T., et al. (2015). Deletion of adenosine A2A receptors from astrocytes disrupts glutamate 
homeostasis leading to psychomotor and cognitive impairment: relevance to schizophrenia. Biol. Psychiatry 78, 763-774. doi: 10.1016/j.biopsych.2015.02.026

Matson, J. L., Sipes, M., Fodstad, J. C., and Fitzgerald, M. E. (2011). Issues in the management of challenging behaviours of adults with autism spectrum disorder. CNS Drugs 25, 597-606. doi: 10.2165/11591700-000000000-0 0000

Matute, C., Alberdi, E., Domercq, M., Perez-Cerda, F., Perez-Samartin, A., and Sanchez-Gomez, M. V. (2001). The link between excitotoxic oligodendroglial death and demyelinating diseases. Trends Neurosci. 24, 224-230. doi: 10.1016/ S0166-2236(00)01746-X

Mayne, M., Fotheringham, J., Yan, H. J., Power, C., Del Bigio, M. R., Peeling, J., et al. (2001). Adenosine A2A receptor activation reduces proinflammatory events and decreases cell death following intracerebral hemorrhage. Ann. Neurol. 49, 727-735. doi: 10.1002/ana.1010

Mei, F., Lehmann-Horn, K., Shen, Y. A., Rankin, K. A., Stebbins, K. J., Lorrain, D. S., et al. (2016a). Accelerated remyelination during inflammatory demyelination prevents axonal loss and improves functional recovery. Elife 5:e18246. doi: 10.7554/eLife.18246

Mei, F., Mayoral, S. R., Nobuta, H., Wang, F., Desponts, C., Lorrain, D. S., et al. (2016b). Identification of the kappa-opioid receptor as a therapeutic target for oligodendrocyte remyelination. J. Neurosci. 36, 7925-7935. doi: 10.1523/ JNEUROSCI.1493-16.2016

Mills, J. H., Thompson, L. F., Mueller, C., Waickman, A. T., Jalkanen, S., Niemela, J., et al. (2008). CD73 is required for efficient entry of lymphocytes into the central nervous system during experimental autoimmune encephalomyelitis. Proc. Natl. Acad. Sci. U.S.A. 105, 9325-9330. doi: 10.1073/pnas.07111 75105

Mizuno, A., Villalobos, M. E., Davies, M. M., Dahl, B. C., and Muller, R. A. (2006). Partially enhanced thalamocortical functional connectivity in autism. Brain Res. 1104, 160-174. doi: 10.1016/j.brainres.2006.05.064

Murray, M. L., Hsia, Y., Glaser, K., Simonoff, E., Murphy, D. G., Asherson, P. J., et al. (2014). Pharmacological treatments prescribed to people with autism spectrum disorder (ASD) in primary health care. Psychopharmacology 231, 1011-1021. doi: 10.1007/s00213-013-3140-7

Noonan, S. K., Haist, F., and Muller, R. A. (2009). Aberrant functional connectivity in autism: evidence from low-frequency BOLD signal fluctuations. Brain Res. 1262, 48-63. doi: 10.1016/j.brainres.2008.12.076

O'Kane, E. M., and Stone, T. W. (1998). Interaction between adenosine A1 and A2 receptor-mediated responses in the rat hippocampus in vitro. Eur. J. Pharmacol. 362, 17-25. doi: 10.1016/S0014-2999(98)00730-4

Othman, T., Yan, H., and Rivkees, S. A. (2003). Oligodendrocytes express functional A1 adenosine receptors that stimulate cellular migration. Glia 44, 166-172. doi: 10.1002/glia.10281

Owley, T., Salt, J., Guter, S., Grieve, A., Walton, L., Ayuyao, N., et al. (2006). A prospective, open-label trial of memantine in the treatment of cognitive, behavioral, and memory dysfunction in pervasive developmental disorders. J. Child Adolesc. Psychopharmacol. 16, 517-524. doi: 10.1089/cap.2006.16.517

Pak, M. A., Haas, H. L., Decking, U. K. M., and Schrader, J. (1994). Inhibition of adenosine kinase increases endogenous adenosine and depresses neuronal activity in hippocampal slices. Neuropharmacology 33, 1049-1053. doi: 10.1016/ 0028-3908(94)90142-2

Paterniti, I., Melani, A., Cipriani, S., Corti, F., Mello, T., Mazzon, E., et al. (2011). Selective adenosine A2A receptor agonists and antagonists protect against spinal cord injury through peripheral and central effects. J. Neuroinflammation 8:31. doi: $10.1186 / 1742-2094-8-31$

Paval, D. (2017). A dopamine hypothesis of autism spectrum disorder. Dev. Neurosci. 39, 355-360. doi: 10.1159/000478725

Richetto, J., Chesters, R., Cattaneo, A., Labouesse, M. A., Gutierrez, A. M. C., Wood, T. C., et al. (2017). Genome-wide transcriptional profiling and structural magnetic resonance imaging in the maternal immune activation model of neurodevelopmental disorders. Cereb. Cortex 27, 3397-3413. doi: 10.1093/ cercor/bhw320

Safarzadeh, E., Jadidi-Niaragh, F., Motallebnezhad, M., and Yousefi, M. (2016). The role of adenosine and adenosine receptors in the immunopathogenesis of multiple sclerosis. Inflamm. Res. 65, 511-520. doi: 10.1007/s00011-016-0936-z

Schubert, P., Komp, W., and Kreutzberg, G. W. (1979). Correlation of 5'nucleotidase activity and selective transneuronal transfer of adenosine in the hippocampus. Brain Res. 168, 419-424. doi: 10.1016/0006-8993(79)90186-0
Sebastiao, A. M., and Ribeiro, J. A. (1996). Adenosine A2 receptor-mediated excitatory actions on the nervous system. Prog. Neurobiol. 48, 167-189. doi: 10.1016/0301-0082(95)00035-6

Sebastiao, A. M., and Ribeiro, J. A. (2000). Fine-tuning neuromodulation by adenosine. Trends Pharmacol. Sci. 21, 341-346. doi: 10.1016/S0165-6147(00) 01517-0

Sebastiao, A. M., and Ribeiro, J. A. (2009). Adenosine receptors and the central nervous system. Handb. Exp. Pharmacol. 193, 471-534. doi: 10.1007/978-3540-89615-9_16

Seeman, P. (2010). Dopamine D2 receptors as treatment targets in schizophrenia. Clin. Schizophr. Relat. Psychoses 4, 56-73. doi: 10.3371/CSRP.4.1.5

Setzu, A., Ffrench-Constant, C., and Franklin, R. J. (2004). CNS axons retain their competence for myelination throughout life. Glia 45, 307-311. doi: 10.1002/ glia.10321

Setzu, A., Lathia, J. D., Zhao, C., Wells, K., Rao, M. S., Ffrench-Constant, C., et al. (2006). Inflammation stimulates myelination by transplanted oligodendrocyte precursor cells. Glia 54, 297-303. doi: 10.1002/glia.20371

Shen, H. Y., Canas, P. M., Garcia-Sanz, P., Lan, J. Q., Boison, D., Moratalla, R., et al. (2013). Adenosine A2A receptors in striatal glutamatergic terminals and GABAergic neurons oppositely modulate psychostimulant action and DARPP-32 phosphorylation. PLoS One 8:e80902. doi: 10.1371/journal.pone. 0080902

Shen, H. Y., and Chen, J. F. (2009). Adenosine A2A receptors in psychopharmacology: modulators of bahavior, mood, and cognition. Curr. Neuropharmacol. 7, 195-206. doi: 10.2174/157015909789152191

Shen, H. Y., Coelho, J. E., Ohtsuka, N., Canas, P. M., Day, Y. J., Huang, Q. Y., et al. (2008). A critical role of the adenosine A2A receptor in extrastriatal neurons in modulating psychomotor activity as revealed by opposite phenotypes of striatum and forebrain A2A receptor knock-outs. J. Neurosci. 28, 2970-2975. doi: 10.1523/JNEUROSCI.5255-07.2008

Shen, H. Y., Singer, P., Lytle, N., Wei, C. J., Lan, J. Q., Williams-Karnesky, R. L., et al. (2012). Adenosine augmentation ameliorates psychotic and cognitive endophenotypes of schizophrenia. J. Clin. Invest. 122, 2567-2577. doi: 10.1172/ JCI62378

Shih, P., Shen, M., Ottl, B., Keehn, B., Gaffrey, M. S., and Muller, R. A. (2010). Atypical network connectivity for imitation in autism spectrum disorder. Neuropsychologia 48, 2931-2939. doi: 10.1016/j.neuropsychologia.2010.05.035

Si, Q. S., Nakamura, Y., Schubert, P., Rudolphi, K., and Kataoka, K. (1996). Adenosine and propentofylline inhibit the proliferation of cultured microglial cells. Exp. Neurol. 137, 345-349. doi: 10.1006/exnr.1996.0035

Sitkovsky, M. V., Lukashev, D., Apasov, S., Kojima, H., Koshiba, M., Caldwell, C., et al. (2004). Physiological control of immune response and inflammatory tissue damage by hypoxia-inducible factors and adenosine A2A receptors. Annu. Rev. Immunol. 22, 657-682. doi: 10.1146/annurev.immunol.22.012703.104731

Snyder, S. H. (1985). Adenosine as a neuromodulator. Annu. Rev. Neurosci. 8, 103-124. doi: 10.1146/annurev.ne.08.030185.000535

Sperlagh, B., and Vizi, E. S. (2011). The role of extracellular adenosine in chemical neurotransmission in the hippocampus and Basal Ganglia: pharmacological and clinical aspects. Curr. Top. Med. Chem. 11, 1034-1046. doi: 10.2174/ 156802611795347564

Stevens, B., Porta, S., Haak, L. L., Gallo, V., and Fields, R. D. (2002). Adenosine: a neuron-glial transmitter promoting myelination in the CNS in response to action potentials. Neuron 36, 855-868. doi: 10.1016/S0896-6273(02) 01067-X

Stolerman, E. S., Smith, B., Chaubey, A., and Jones, J. R. (2016). CHD8 intragenic deletion associated with autism spectrum disorder. Eur. J. Med. Genet. 59, 189-194. doi: 10.1016/j.ejmg.2016.02.010

Stubbs, G., Litt, M., Lis, E., Jackson, R., Voth, W., Lindberg, A., et al. (1982). Adenosine deaminase activity decreased in autism. J. Am. Acad. Child Psychiatry 21, 71-74. doi: 10.1097/00004583-198201000-00012

Tanimura, Y., Vaziri, S., and Lewis, M. H. (2010). Indirect basal ganglia pathway mediation of repetitive behavior: attenuation by adenosine receptor agonists. Behav. Brain Res. 210, 116-122. doi: 10.1016/j.bbr.2010.02.030

Tsutsui, S., Schnermann, J., Noorbakhsh, F., Henry, S., Yong, V. W., Winston, B. W., et al. (2004). A1 adenosine receptor upregulation and activation attenuates neuroinflammation and demyelination in a model of multiple sclerosis. J. Neurosci. 24, 1521-1529. doi: 10.1523/JNEUROSCI.4271-03. 2004 
Turner, C. P., Yan, H., Schwartz, M., Othman, T., and Rivkees, S. A. (2002). A1 adenosine receptor activation induces ventriculomegaly and white matter loss. Neuroreport 13, 1199-1204. doi: 10.1097/00001756-20020702000026

Turner, K. C., Frost, L., Linsenbardt, D., McIlroy, J. R., and Muller, R. A. (2006). Atypically diffuse functional connectivity between caudate nuclei and cerebral cortex in autism. Behav. Brain Funct. 2:34.

Vincenzi, F., Corciulo, C., Targa, M., Merighi, S., Gessi, S., Casetta, I., et al. (2013). Multiple sclerosis lymphocytes upregulate A2A adenosine receptors that are antiinflammatory when stimulated. Eur. J. Immunol. 3, 2206-2216. doi: 10.1002/eji.201343314

Wegiel, J., Kuchna, I., Nowicki, K., Imaki, H., Marchi, E., Ma, S. Y., et al. (2010). The neuropathology of autism: defects of neurogenesis and neuronal migration, and dysplastic changes. Acta Neuropathol. 119, 755-770. doi: 10.1007/s00401010-0655-4

Wei, W., Du, C., Lv, J., Zhao, G., Li, Z., Wu, Z., et al. (2013). Blocking $\mathrm{A} 2 \mathrm{~B}$ adenosine receptor alleviates pathogenesis of experimental autoimmune encephalomyelitis via inhibition of IL-6 production and Th17 differentiation. J. Immunol. 190, 138-146. doi: 10.4049/jimmunol. 1103721

Yao, S. Q., Li, Z. Z., Huang, Q. Y., Li, F., Wang, Z. W., Augusto, E., et al. (2012). Genetic inactivation of the adenosine $\mathrm{A}(2 \mathrm{~A})$ receptor exacerbates brain damage in mice with experimental autoimmune encephalomyelitis. J. Neurochem. 123, 100-112. doi: 10.1111/j.1471-4159.2012.07807.x

Zhao, C., Dong, C., Frah, M., Deng, Y., Marie, C., Zhang, F., et al. (2018). Dual requirement of CHD8 for chromatin landscape establishment and histone methyltransferase recruitment to promote CNS myelination and repair. Dev. Cell 45, 753-768.e8. doi: 10.1016/j.devcel.2018.05.022

Zhu, C. B., Lindler, K. M., Campbell, N. G., Sutcliffe, J. S., Hewlett, W. A., and Blakely, R. D. (2011). Colocalization and regulated physical association of presynaptic serotonin transporters with $\mathrm{A}(3)$ adenosine receptors. $\mathrm{Mol}$. Pharmacol. 80, 458-465. doi: 10.1124/mol.111.071399

Conflict of Interest Statement: The authors declare that the research was conducted in the absence of any commercial or financial relationships that could be construed as a potential conflict of interest.

Copyright (c) 2018 Shen, Huang, Reemmer and Xiao. This is an open-access article distributed under the terms of the Creative Commons Attribution License (CC BY). The use, distribution or reproduction in other forums is permitted, provided the original author(s) and the copyright owner(s) are credited and that the original publication in this journal is cited, in accordance with accepted academic practice. No use, distribution or reproduction is permitted which does not comply with these terms. 